\title{
El cuerpo del delito: de Tōkyō monogatari a Tokyo-Ga
}

\section{Corpus delicti: From Tōkyō Monogatari to Tokyo-Ga}

\author{
German A. Duarte 1 \\ Recibido: 05-04-2017 - Aceptado: 04-07-2017 \\ DOI: https://doi.org/10.26441/RC16.2-2017-A8
}

RESUMEN: En este ensayo se analizarán las características de la obra de Ozu, así como la relación que este director estableció con la cámara cinematográfica. Veremos de qué forma su obra atestigua la gran transformación que vivió la sociedad japonesa durante la segunda mitad del siglo pasado. En la segunda parte, se analizará Tokyo-Ga (1983) y el particular interés que Wim Wenders presta a las transformaciones sociales del Japón de la década de 1980. Nos cuestionaremos sobre el efecto que las imágenes video-electrónicas estaban teniendo en el contexto socio-tecnológico analizado por Wenders. De igual manera, se indagará sobre la desaparición de lo real causada por los simulacros que inesperadamente empezaron a poblar la realidad. Por último, se desarrollarán algunas reflexiones sobre la condición mediática analizada por Wenders en Tokyo-Ga y, a través de ellas, se analizará el pasaje de una condición video-electrónica a nuestra condición mediática actual.

Palabras clave: Critical Media Studies; Jean Baudrillard; Wim Wenders; Yasujirō Ozu.

ABSTRACT: This essay will deal with the main characteristics of Ozu's oeuvre, mainly with the interesting relationship that he established with the cinematographic camera. It will be analyzed the way in which his oeuvre deals with the important transformation that the Japanese society underwent during the second half of the last century. In the second part, the essay will deal with Wenders' documentary film Tokyo-Ga (1983) and his analysis of social transformations in Japan during the Eighties. Following this framework, the effects of video-electronic images on the socio-technological context analyzed by Wenders will be examined. Further, I will inquire into the way in which simulacra began to populate our reality and seemingly replace the real. To conclude, through some reflections on the media condition highlighted by Wenders in Tokyo-Ga, I will also analyze the passage from the video-electronic condition to our current media condition.

Keywords: Critical Media Studies; Jean Baudrillard; Wim Wenders; Yasujirō Ozu.

1 German A. Duarte es Doctor en Medios de comunicación y estudios cinematográficos por la Ruhr-Universität Bochum, Alemania. Actualmente es titular de la cátedra de Historia y crítica cinematográfica y de medios audiovisuales en la facultad de Design and Art en la Free University of Bozen-Bolzano, Italia. GDuarte@unibz.it, http:// orcid.org/0000-0002-0902-7790 
If only it were possible to film like that - I thought to myself - like when you open your eyes sometimes. Just to look, without wanting to prove anything. Wim Wenders, Tokyo-Ga (1983)

\section{Introducción}

Tokyo-ga (1983) se afianza en una serie de obras -que podríamos llamar exploratorias- en las que Wenders reflexiona sobre los efectos que la tecnología de video estaba teniendo sobre las formas narrativas, y, por ende, sobre el conjunto de la sociedad. TokyoGa sucede a Room 666 (1982), documental con el que Wenders, a través de una serie de testimonios libres -el entrevistado se encontraba solo frente a la cámara-, se cuestiona sobre el futuro del cine. Una inquietud legítima, si pensamos que durante la realización de Room 666, el video, como tecnología híbrida o de pasaje, empezaba a transformar las formas narrativas en el campo audiovisual (Spielmann, 2005). Sin embargo, hoy podríamos afirmar que es innecesario cuestionarse sobre el futuro del cine.

De hecho, las teorías de Henri Bergson, que en los últimos años han tomado gran relevancia en el campo de los estudios cinematográficos y de comunicación, nos permiten ver que tanto la imagen cinematográfica como la percepción de la realidad son un constante presente en devenir, una constante mutación que establece de cierta forma un solo tiempo presente, el cual reina sobre la percepción del pasado, y que, a su vez, como tiempo reinante, determina inmediatamente el futuro.

Todo momento es un momento de transformación en el que el sujeto se convierte en un punto de vista sobre una serie de mutaciones (Thrift, 2007). Su etimología lo indica claramente. De hecho, la palabra latina 'momentum' entrelaza estrechamente su raíz con el vocablo 'movimentum'. En consecuencia, el espacio semántico del vocablo 'momento' abarca una noción temporal, un breve movimiento de tiempo o la duración de un simple movimiento. Esto, como nos lo enseña Bergson, es una condición universal que la cámara cinematográfica, siendo una tecnología, ergo una extensión de los sentidos, termina por plasmar en su forma de representar la realidad (McLuhan, 1994).

Así como la imagen cinematográfica, que solo conoce el tiempo presente, el cine, como práctica social, solo conoce esa declinación. Carece de futuro simplemente porque el futuro constituye, bajo la visión bergsoniana, nuestro presente en devenir, y sus formas narrativas y de interacción derivan directamente de un contexto tecnológico preciso y presente. Por el contrario, lo que el cine conoce muy bien son unos indelebles rastros del pasado, que declinamos en nuestro 
único tiempo presente y desciframos a través de los códigos de lectura o cuadros sociales, desarrollados en nuestro contexto tecnológico. De hecho, la imagen cinematográfica, que no nace con fines documentales, y tanto menos con fines de entretenimiento popular, desde sus inicios se convirtió en el instrumento evocador del pasado por excelencia (Bazin, 2008, p.14).

La imagen cinematográfica evoca; es decir, para ser fieles a su etimología latina, (del latín evocare compuesto de $e x=$ fuera y vocare $=$ llamar), declina en nuestro presente un tiempo fuera de la realidad, pero que se vuelve realidad porque se materializa en nuestro universo semántico. Esa realidad traída o declinada en nuestro eterno devenir se descifra a través de nuestro cuadro social. Y en este sistema de evocación del pasado, el soporte se ha hecho indispensable.

La historia no existe en ausencia de soporte. De hecho, como disciplina, la historia se funda sobre el estudio de documentos escritos. En consecuencia, el tiempo precedente a la escritura es noto como prehistoria ${ }^{2}$. Como afirma Maurice Halbwachs, la historia es el registro de eventos del pasado de los cuales hemos guardado un recuerdo. Pero mientras realizamos este proceso, mientras registramos, limitamos nuestro saber histórico a las rupturas, a las dife- rencias. La historia, a diferencia de la memoria, no representa una corriente de pensamiento continuo, no es un flujo constante (Halbwachs, 1997, p.131); la historia adquiere una cierta linealidad exclusivamente mediante la estructura narrativa que le conferimos. La historia es en sí una serie de rupturas discontinuas, una serie de eventos que marcan una diferencia (Lefebvre, 1999). He ahí la relevancia que adquiere Tokyio-Ga en este ensayo. Tokyio-Ga se trata de un complejo sistema de rupturas discontinuas que encuentran como hilo conductor la gran obra de Yasujirō Ozu, en particular su Cuentos de Tokio (Tōkyō monogatari, 1953).

En la primera parte de este ensayo se analizará brevemente las características de la obra de Ozu, su particular manera de componer el espacio narrativo, así como la relación que este maestro del cine japonés estableció con la cámara cinematográfica. También se indagará de qué forma la obra de Ozu se convierte en un documento histórico que atestigua la violenta transformación que vivió la sociedad japonesa durante la segunda mitad del siglo pasado. En la segunda parte, será analizada Tokyo-Ga y el especial interés que Wim Wenders presta a las transformaciones sociales del Japón de los años 1980. Por último, analizaremos el papel que desempeñó la tecnología de video en los fenómenos

2 Mario Liverani ve el origen de la historia en el nacimiento de la ciudad, ya que esta generó una estratificación socio-económica compleja. Por esta razón, Liverani afirma que no es el hecho de que la escritura, como nueva tecnología, haya puesto a nuestra disposición una fuente de información precisa lo que marcó el inicio de la historia. Para Liverani, el nacimiento de la historia reside en la ciudad porque es ahí donde se genera una interacción compleja entre grupos de personas que pertenecían a una misma comunidad (Liverani, 2009, p.108). 
sociales resaltados por Wenders en su obra. Nos cuestionaremos sobre la imposibilidad de efectuar una representación expresada por Wenders en Tokyo$G a$, y el efecto que las imágenes video-electrónicas estaban ejerciendo en el contexto socio-tecnológico analizado por Wenders. De igual manera, se indagará sobre la desaparición de lo real causada por los simulacros que inesperadamente empezaron a poblar nuestra realidad.

\section{Yasujirō Ozu}

En el Japón del siglo XX la introducción de la cinematografía fue percibida como un síntoma de decadencia y de empobrecimiento cultural ejercido por la occidentalización que encarnaba la imagen en movimiento. Yasujirō Ozu, reconocido como el autor más tradicional y conservador del rico universo cinematográfico japonés (Richie, 1962, pp.102-105), a veces injustamente catalogado como un reaccionario, empleó esta nueva tecnología en su más pura comprensión: la cámara, para Ozu, era una mera prolongación del ojo y del entendimiento humano. Significaba una puerta abierta a una nueva forma de entender la realidad, y, en la realidad de Ozu, el ser humano encarnaba el centro. La cámara siempre a la altura humana -a la altura del personaje sentado sobre el tatami-, siempre concediéndole la posición central al ser humano, siempre adaptándose a la visión humana a través del obsesivo uso del objetivo de 50 milímetros. Estos fueron los imperativos que rigieron con absoluto rigor la extensa obra de Ozu.
Ozu realizó 54 películas en 35 años. Inició su carrera en 1923 en la Shōchiku, los mismos estudios cinematográficos de Kenji Mizoguchi, Keisuke Kinoshita, Yoji Yamada y Akira Kurosawa, entre otros. Como asistente en el departamento cinematográfico, Ozu impulsó su carrera. En 1927, el joven Ozu realiza su primera película, $L a$ espada de la penitencia (Zange no Yaiba). Con esta obra no solo marcó el inicio de su obra, sino también el inicio de una gran amistad con Kōgo Noda, el guionista que colaborará con Ozu durante toda su vida. Como director, durante los primeros años, Ozu se concentró sobre temas románticos y algunos temas sociales impuestos por la sociedad de producción. Fue en 1930, con la realización de La señorita (Ojosan), que Ozu, aún teniendo como núcleo central la tradición, empieza a acercarse a un tipo de producción norteamericana.

La década de 1930 representa una gran transformación en su obra. Ozu se empieza a acercar al shomin y el shominggeki, el género que caracterizará su obra del posguerra. De hecho, es durante la década de 1930 que Ozu se interesa por la realidad social de Japón incentivando en sus obras la aparición de personajes populares, desempleados, estudiantes buscando una ocupación laboral. Ciertamente, el interés social impone un análisis sobre las relaciones de fuerza, de explotación y de injusticia. Podríamos decir que la película más relevante de ese periodo es Una mujer de Tokio (Tokio no onna, 1933), cuyo personaje principal es una mujer que se prostituye para pagar la educación de 
su hermano. En estas obras se puede observar el inicio de las temáticas que Ozu desarrollará durante el periodo posbélico, que manifestaban un alto interés por la familia, vista como microcosmos de las relaciones de fuerza y autoridad, así como el contraste entre tradición y modernidad (Anderson, Richie, 1960, p.51).

Posiblemente lo que generaba tan duras críticas a la obra de Ozu era la humanidad de sus personajes, resaltados por la posición de la cámara y el uso riguroso del objetivo de $50 \mathrm{~mm}$, que ponía al ser humano de cierta forma en superioridad con la tecnología. El Japón de Ozu no podía concebir al ser humano en superioridad con la tecnología. La sociedad japonesa no era capaz de declinar en su tiempo presente el cosmos lleno de sentido y de humanidad creado por Ozu. El Japón posbélico había vivido una ruptura radical, y esa cultura milenaria ya no era declinable en su presente.

A través del Shomin-geki, Ozu encontró la forma de plantear una crítica a la ruptura que vivía la sociedad japonesa. El Shomin es un género que representa la vida del proletariado, de la clase media. Este género encuentra sus raíces en el melodrama y la comedia de los años 1920 y 1930, y, después de la Segunda Guerra Mundial, de las manos de Mikio Naruse y del propio Yasujirō Ozu -sus dos mayores exponentes-, empieza a convertirse en un género que desarrolla un contenido singularmente de crítica social. Los temas centrales son la clase obrera y la vida de gente común. De hecho, la palabra Shomin (庶民) significa gente común, la masa. Sin embargo, en sus obras Ozu establece, a través de lo particular, un claro reflejo de lo universal. Como afirma Richie, "In every $O z u$ film, the whole world exists in one family. The ends of the earth are no more distant than outside the house". (Richie, 1962, p.359). Por ejemplo, la autoridad del padre de familia es un claro reflejo de la autoridad política o policial. Las tensiones, el autoritarismo y los abusos que se presentan en el núcleo familiar no solo reflejan claramente las tensiones sociales en una escala mayor, sino también exponen palmariamente la mutación de la sociedad japonesa, convirtiendo así la obra de Ozu en documento histórico a todos sus efectos.

La obra de Ozu es un testigo de la transformación -de la mutación- de una sociedad tradicional que se abría a la cultura occidental y que en pocos años no solo la asimilaría sino que se convertía, a través de la producción y creación de aparatos tecnológicos, en una parte fundamental de ella. Es precisamente esa diferencia, esa ruptura, la que plasma Ozu en su obra, que, constituyendo un documento histórico, pone al ser humano en la mitad de esa violenta transformación social. No es un simple capricho de autor el querer despojar sus historias del drama o de la misma noción de narración. De hecho, Ozu afirmaba que las películas con trama lo aburrían (Richie, 1959, p.21). Con respecto a Otoño tardío (Akibiyori, 1960) Ozu afirmaba: "I want to portray a man's character by eliminating all the dramatic devices. I want to make people feel what life is like without 
delineating all the dramatic ups and down". (Ozu, 1970, p. 5).

En la última fase de la obra de Ozu (1950-1962), la trama representaba un instrumento artificial que pervertía la imagen nítida del ser humano. La trama se tenía que disolver en la composición espacial, en la profundidad de las imágenes, en la persona sentada sobre el tatami y la cámara, a menos de un metro de altura. Sin embargo, el rechazo de la trama no significaba necesariamente la ausencia de comunicación (Barthes, 2002, p.355). Podríamos entender la necesidad de despojar su obra de la trama como la necesidad de acercarse a una representación de una condición humana que estaba mutando violentamente. Es tal vez ese el motivo de la austeridad técnica de sus películas, la absoluta necesidad de cancelar la tecnología que empezaba a invadir cada espacio, cada relación social del Japón de posguerra. El rechazo de la trama, junto con la necesidad de poner al ser humano al centro de su universo fílmico, eran síntomas de que el ser humano se estaba disolviendo en su propia representación. La trama, como bien lo dice $\mathrm{Ozu}$, nos aleja de lo que es realmente la vida.

Durante la década de 1940, empezamos a ver en la obra de Ozu un acto quasi de resistencia al desarrollo tecnológico en el campo cinematográfico. Desde Hermanos y hermanas de la familia Toda (Todake no kyodai, 1941), hasta El sabor del sake (Sanma no aji, 1961) Ozu se radicaliza mediante la afirmación de su estilo. De hecho, renuncia por completo a los movimientos de cámara, renun- cia también a los primeros planos, al montaje con efectos y a las disolvencias. Las transiciones que usa son elaboradas no tanto en función de la diégesis, sino en función de una prolongación emocional. También notamos que durante este periodo los actores se dirigen directamente al espectador, miran directamente a la cámara. La actuación se caracteriza por la casi ausencia de expresiones. Se podría afirmar que durante su último periodo Ozu propone una cierta reelaboración del teatro $N \bar{o}$. El reparto, que minimiza sus expresiones faciales, simula de cierta forma las máscaras que caracterizan dicha forma teatral. También vemos que Ozu desarrolla sus escenas en espacios internos bien definidos. Los espacios donde se desarrolla la acción priman de cierta forma sobre los cánones de continuidad del montaje. En otras palabras, vemos que el espacio determina la acción y su construcción cinematográfica, imponiendo jump cuts a la hora del montaje.

\section{Tōkyō monogatari}

Cuentos de Tokio (Tōkyō monogatari, 1953) representa un claro ejemplo de la consolidación de la forma narrativa desarrollada por Ozu durante toda su carrera. En esta película, Ozu logra llevar a la imagen las transformaciones radicales que vivía Japón durante la década de $1950^{3}$.

Shūkichi y Tomi Hirayama, llegados a la vejez, organizan un largo viaje desde Onomichi, pueblo situado sobre el litoral del Mar interior de Seto, a la capital nipona, ciudad próspera y residencia de los hijos de la pareja de ancianos. 
Al llegar a Tokio, se hospedan en la casa de su primogénito Kōichi, médico pediatra que ejerce en su barrio, un suburbio popular de Tokio. Poco después, se hospedan en la casa de su hija mayor, Shige, quien trabaja como peluquera.

Ya desde su llegada, los ancianos se dan cuenta de que sus hijos no tienen tiempo para dedicarles y que su presencia en la gran ciudad les molesta. La única persona que los lleva a conocer la ciudad y les dedica tiempo a los dos ancianos es Noriko, viuda de Shōji, segundogénito de la pareja que ocho años atrás había muerto en la guerra. Noriko, joven y bella, decidió no volver a casarse y vive en el recuerdo del difunto marido. Es durante los días que los dos ancianos pasan en Tokio que Ozu expone los grandes cambios sociales que experimentaba la sociedad nipona. Vemos, por ejemplo, los edificios en construcción, el desarrollo industrial que determina el éxodo de personas jóvenes de todas las provincias hacia la capital. Ejemplo de ello, los propios hijos de Shūkichi y Tomi Hirayama, que se abrieron un espacio en el mundo competitivo de Tokio.

Ozu plantea un fenómeno social de complejidad inmensa, y lo expone a través de la forma en que la concentración de la producción en la urbe disolvía el $i e^{4}$ japonés, otrora base de la jurisprudencia japonesa. La transición al sistema de familia nuclear disolvió por completo la estructura familiar tradicional, y esto se refleja claramente en la soledad de la pareja de ancianos, que vieron a sus hijos emigrar a la gran ciudad en busca de una mejor posición económica. Ozu nos muestra que la abolición del ie ejerció una profunda transformación sobre los sentimientos familiares, pero esa transformación sufrió una agravante aceleración debido a la concentración de los centros de producción en las grandes ciudades. Es por esta razón que Tōkyō monogatari trata

3 Es importante recordar que en el Extremo Oriente la década de 1950 se estrena con la Guerra de Corea -el 25 de junio, los T-34 norcoreanos violan el límite del $38^{\circ}$ paralelo que las Naciones Unidas había establecido como frontera entre las dos Coreas- y con el final de la ocupación militar norteamericana en Japón, acordada en la Conferencia de San Francisco para 1952. Durante esa primera mitad del decenio, Japón gozó de un fuerte apoyo económico norteamericano. Una especie de Plan Marshall fue destinado a Japón con el claro objetivo de evitar una crisis económica que pudiera favorecer a la ideología comunista. De esta manera, la débil economía posbélica nipona encontró un gran impulso. La industria pesada fue la primera beneficiada, y, a través de ella, la totalidad de la población empezó progresivamente a gozar de esa nueva riqueza. Se estima que entre 1954 y 1960 la inversión privada se cuadriplicó y la exportación se duplicó. Este periodo de crecimiento económico es conocido como el "Jimmu boom", ya que un tal crecimiento y bienestar se remontaba a la hipotética llegada al poder del primer emperador del Japón, el emperador Jimmu, que reinaría desde el año 660 antes de Cristo. Durante este boom económico se emprendió la reconstrucción de las grandes ciudades, en especial manera la ciudad de Tokio. Esta reconstrucción, de la mano con la industrialización, transformó radicalmente la capital del país. En el filme en cuestión, Tōkyō monogatari, se observa claramente la presencia insistente de las altas chimeneas, signo del desarrollo industrial que marcaría la ciudad de Tokio (Tomasi, 1996).

4 El término ie puede también ser traducido como casa, residencia, morada o familia, pero su significado abarca un campo semántico más vasto. Litigios legales, tanto civiles como penales, implicaban a la familia en su totalidad y no solo al individuo. El concepto de familia tradicional en Japón, establecido por el código civil, era un patriarcado que se componía por los abuelos, su hijo y su esposa, y los hijos de estos. El sistema fue abolido por los Aliados, quienes substituyeron el ie por el sistema de familia nuclear (Sugimoto, 2010). 
sobre la influencia que tiene la ciudad sobre el carácter de los personajes (Bordwel, 1988, p.331). Y esta transformación, como afirma Tomasi, pasa a través de la "falta de tiempo", verdadero leitmotiv en la película.

En el Japón de la reconstrucción, los jóvenes carecen de tiempo. La competencia es ardua, y crearse un espacio en la máquina productiva japonesa absorbe por completo los días de estos jóvenes; muchos de ellos, como es el caso de Kōichi, Shige y Noriko, ven al país enriquecerse, mientras ellos viven en la pobreza. La competencia feroz termina por destruir la esfera afectiva de los habitantes de ese nuevo Japón (Tomasi, 1996, pp.15-20).

Las primeras escenas de Tōkyō monogatari componen la introducción de la película de Wenders, que nace, como él mismo afirma, por la curiosidad de ver si todavía existía algo del mundo de Ozu veinte años después de su muerte. En Tokyo-Ga, Wenders busca la humanidad que se disolvía en las imágenes de la obra de Ozu. La humanidad que Ozu luchaba por conservar y que se desvanecía en el eterno devenir de la representación.

\section{Pachinko Parlor}

Tokio era un sueño, nos dice Wenders al inicio de su película, era un sueño hecho con imágenes de la obra de Ozu. Usando la cámara como un cuaderno de notas, como un informe arqueológico, Wenders quería encontrar en el Japón de la década de 1980 los rastros del lugar creado por Ozu. Sin embargo, como afirma Wenders al inicio de Tokyo-
$G a$, el espacio creado por Ozu, "que solo puede residir en el reino de la imaginación", ya no existe. Wenders se convierte en un arqueólogo, un estudioso de lo antiguo, y, aunque la realidad de Ozu no dista significativamente de la misión arqueológica de Wenders, ésta posiblemente ya había desaparecido por completo: era una realidad que se había esfumado.

Poco a poco, Tokyo-Ga se convierte en una suerte de thriller en el que el cuerpo del delito nunca será encontrado. El cuerpo del delito en Tokyo-Ga es lo real, eso que se había desvanecido con la ilusión, con el simulacro. Como afirma Baudrillard; "D'ailleurs, dans ce livre noir de la disparition du réel, ni les mobiles ni les auteurs n'ont pu être repérés, et le cadavre du réel lui-même n'a jamais été retrouvé". (Baudrillard, 1995, p.10).

Desde las primeras imágenes vemos la urbe moderna, sobrepoblada, las concurridas estaciones de metro, los gestos repetitivos de las personas, casi tics que acompañan toda la película. La voz fuera de campo de Wenders describe a las personas como sonámbulos que caminan por los largos y abarrotados corredores del metro, por las iluminadas calles comerciales. Son sonámbulos que habitan un espacio que no concibe el vacío; materialización del horror vacui. Luces, publicidades, pantallas de televisión en los automóviles, en las calles, en los metros. No existe el silencio, no existe el vacío, aparentemente. El vacío es, como nos muestra Wenders, interno e infinito. Es en una sala de Pachinko que podemos observarlo en su plenitud. El vacío lleva al olvido la condición 
humana precedente, ahora inexistente, y que hoy se encuentra en blanco y negro en la obra de Yasujirō Ozu, una obra que cromáticamente no hacía parte del imaginario de la urbe moderna: Tokio.

El Pachinko, que Rolan Barthes describe en su texto dedicado a sus reflexiones durante su estadía en Japón, L'empire des signes, es una máquina tragamonedas en la que el jugador inserta unas bolas metálicas. El jugador, con una mano las inserta en la máquina, y con la otra, gracias a un resorte, impulsa la bola que recorre un trayecto lleno de obstáculos. Si la fuerza con la que el jugador envía la bola al mecanismo del Pachinko es precisa, ni muy fuerte ni muy débil, la bola genera una lluvia de otras bolas metálicas que caen en las manos del jugador. Solo queda recomenzar, o cambiar la ganancia irrisoria por un paquete de cigarrillos, una chocolatina, o una naranja (Barthes, 2002, p.371). Como afirma Wenders, el Pachinko es un juego solitario, una suerte de hipnosis colectiva que refuerza, en su colectividad, el sentimiento de soledad.

El jugador, a solas con la máquina, cae en un estado hipnótico que genera una extraña sensación de felicidad. En este juego ganar es importante, y la ganancia es, al final de cuentas, la abstracción del tiempo.

Winning is hardly important. But time passes. You lose touch with yourself for a while and merge with the machine, and perhaps you forget what you always wanted to forget. This game first appeared after the lost war, when the Japanese people had a national trauma to forget

(Wenders, 1983 - Tokyo-Ga).

Como descrito por Barthes, en este juego colectivo pero solitario, cada jugador se sienta en frente de una máquina, y, sin siquiera mirar a su vecino, empieza a insertar las bolas metálicas.

Las salas de Pachinko parecen una fábrica, una cadena de montaje. Movimientos repetitivos, seriales, que moldean el cuerpo de sus jugadores, ahora ya sonámbulos. En su recursividad, el Pachinko se convierte en una máquina del olvido. Repitiendo la misma acción, el jugador se anula. Como en el sueño de producción taylorista, el sujeto se desvanece en el objeto productivo. Las imágenes del Pachinko, tanto esas de Tokyo-Ga como las descritas por Barthes, son claros testigos de la posguerra japonesa. Diseñan un imaginario modelado por la destrucción de la explosión nuclear, por la MAD (Mutual Assured Destruction) que encarnaba el mensaje de disuasión, pero, sobre todo, que empezaba a desplazar toda actividad humana al reino de la información. En palabras de Derrick de Kerckhove:

La bomba atomica, per dirla à la McLuhan, funzionava come l'arma perfetta che non si doveva mai utilizzare, perché la sua efficacia era nel messaggio di dissuasione. Con la bomba atomica la propaganda supera lo sforzo militare. L'arma diviene informazione pura e si rovescia nel suo opposto: il 'peacekeeping' è infatti un'arma che non permette di fare la guerra (Monico, De Kerckhove, 2016, p.2).

Las escenas del Pachinko en Tokyo$G a$ hoy nos parecen imágenes de un 
mundo lejano, de una realidad ya inexistente. En el Pachinko vemos un contexto tecnológico desapareciendo, así como una condición humana sumergida en el trauma de la posguerra. Podríamos analizarlo como un juego que recuerda el extinguido sistema de producción material donde se enfrentaban repeticiones mecánicas. El sujeto entra en un estado de gestos repetitivos, gracias a los cuales se abstrae y olvida, recordándonos las reflexiones de Deleuze sobre la repetición, que según él no era otra cosa que la diferencia sin concepto.

Usando la síntesis de Hume, Deleuze afirma lo siguiente: "La répétition ne change rien dans l'objet qui se répète, mais elle change quelque chose dans l'esprit qui la contemple”. (Deleuze, 1968, p.96). La repetición, como afirma Deleuze, implica diferencia. La repetición es en cierta forma un tipo de intuición que encarna el poder del instante, y que a su vez determina la realidad del tiempo en la que el ser humano es consciente de su existencia. Como descrito por Gaston Bachelard: "Si mon être ne prend conscience de soi que dans l'instant présente, comment ne pas voir que l'instant présent est le seul domaine où la réalité s'éprouve?" (Bachelard, 1931, p.14).

La repetición, recursividad o serialidad afecta directamente a la psique del sujeto, o usando las palabras de Hume, al espíritu del sujeto: “(...) repetition neither discovers nor causes any thing in the objects, but has an influence only in the mind, by that customary transition it produces". (Hume, 2000, p.105). La repetición no afecta al objeto, esta produce una diferencia, algo nuevo en la mente (Deleuze, 1968, p.96).

Deleuze desarrolla esta reflexión a través de los ejemplos de Hume, sobre todo en el caso de repeticiones de tipo AB, AB, AB, AB, AB, A.... Como podemos notar, cada objeto de la secuencia $\mathrm{AB}$ es percibido como un objeto independiente. Sin embargo, la repetición y su serialidad cambia algo en mi mente, ya que cuando observo la 'A', mi mente espera la sucesión, en este caso, la letra 'B'. Es entonces posible afirmar que la subjetividad juega un papel en la constitución de la serialidad. Es la imaginación humana que ejerce un poder de contracción, que no sería otra cosa que el poder de la imaginación que funde los elementos, en nuestro caso, el poder de contracción contrae la letra 'A' y la letra 'B' (Deleuze, 1968, p. 96). Es por esta razón que Deleuze afirma, con respecto al ejemplo apenas mencionado, que la letra 'A' es la síntesis del tiempo. 'A' es el instante que determina la realidad del tiempo, y es a través del tiempo que la humanidad es consciente de su existencia.

La contracción, o síntesis propuesta por Deleuze es una síntesis pasiva, ya que ocurre en la mente del sujeto y es anterior a la memoria y a la reflexión. En consecuencia, para Deleuze, el tiempo es la subjetividad de un sujeto pasivo (Deleuze, 1968, p.97). Podríamos entonces afirmar que el jugador de Pachinko encuentra en la repetición, en la serialidad, la forma de vivir el instante; es decir, una forma de sentir o experimentar la realidad. La serialidad del Pachinko activaría de 
cierta forma la cinestesia que menguaba en la representación. El Pachinko representaría la forma de adquirir una postura corporal perteneciente a la sociedad de producción material, ajena a los simulacros traídos por la sociedad video-electrónica.

Siguiendo la modelación corporal y simulando la organización espacial de la producción taylorista, el Pachinko representaría, como lo afirma Wenders, un instrumento para olvidar la tragedia de la guerra. Ese olvido pasaría exclusivamente a través de la evocación de una postura corporal propia de la condición humana precedente al sobrevuelo del Enola Gay.

En la evocación de la producción material, el Pachinko llevaría al sujeto a un ambiente físico, a una naturaleza transformada, materialmente transformada, por la presencia material del ser humano. Una naturaleza transfigurada por sus edificios, sus calles, los medios de locomoción. La sala de Pachinko cumpliría una función cinestésica, cancelando de la psique la pluralidad de niveles de la realidad del sujeto que habita el Japón posbélico, y, sobre todo, el Japón de la condición video-electrónica. Una pluralidad de niveles que podría resumirse en niveles no solo materiales, sino también inmateriales, imaginarios o informativos, los cuales se encuentran entrelazados y en interrelación (Caronia, 2008, p.98).

El Pachinko es en sí olvido, pero es una forma de olvido que se efectúa a través de la sobre posición de un recuerdo. Con el Pachinko, el sujeto se transforma a través de la serialidad que impone el juego. Es un escamotage a la realidad, un truco eficaz en el que el sujeto elimina su pasado y con esto cancela su presente. Sabemos que el pasado no solamente coexiste con el presente, sino que es la totalidad del pasado, integralmente, que coexiste con cada presente (Deleuze, 1966). El Pachinko, de cierta forma, permitiría la cancelación de la duración (durée) a través de una especie de Satori (悟り) en el que el sujeto establece una suerte de comunión con la máquina: el objeto observado. El Pachinko, al igual que el Satori, es un momento de consciencia profunda en el que el devenir de nuestro presente se manifiesta de tal manera que este elimina la noción de pasado y de futuro (Herrigel, 1999; Suzuki, 1964). Es un devenir bergsoniano que podría entenderse como la plena enajenación (Entfermdung) en la duración (durée).

A diferencia del Satori, que se caracteriza por un despertar intenso del espíritu, el Pachinko aliena y causa olvido. Sin embargo, en su enajenación, el sujeto se abstrae de la duración. El tiempo percibido en el Pachinko es un tiempo nunca encontrado, un futuro que se conjuga en un devenir inexistente. El estado del sujeto en una sala de Pachinko presenta claras analogías con el tiempo desarrollado por la tecnología video-electrónica y la aceleración que esta implica. Un fenómeno de aceleración que Wenders capta plenamente en su película, y que Dorfles describe con estas palabras:

Oggi il tempo non è mai ritrovato perché anche il futuro si verifica prima ancora di incominciare e, alla stessa stregua, la du- 
rée bergsoniana è ormai soprafata da un tempo che "non dura", perché tutto concorre ad abbreviarlo e spezzettarlo (Dorfles, 2008, p. 22).

\section{La muerte de lo real, o la condición video-electrónica}

Desde un punto de vista técnico, la imagen de video crea un continuum. Los puntos de la imagen son una sucesión temporal que compone las líneas del video. Dicho continuum implica que la variación de puntos, que nunca es visible, se constituya en el tiempo y no en el espacio: la imagen encarna un intervalo. El punto en la imagen de video se convierte entonces en una mera metáfora del espacio. En palabras de Engell: Im Punkt findet eine Metaphorisierung des Raums durch Zeit und der Zeit durch Raum zugleich statt. In dieser metaphorischen Funktion gibt eine Rede vom Fernsehbild als Punt-Bild einen Sinn. Nicht der Bildpunkt selbst, sondern seine Dimensionslosigkeit bestimmt daher das elektronische Bild. Der Punt ist nicht „etwas", das mit „anderem“" verknüpft werden könnte, sondern er ist die raumlose Metapher der Verknüpfung des „etwas" mit dem ,anderen“ selbst. (Engell, 1999, p. 471).

La dimensión de la imagen de video no contiene elementos; en palabras de Engell, esta dimensión contiene elementos que "simplemente no pueden continuar su existencia" (Nicht-einfachvorhanden-bleiben-können) (Engell, 1999, p.470). En otras palabras, esta dimensión contiene un continuum, una serie de transformaciones en perpetuo devenir. En consecuencia, la imagen de video desarrolla una imagen actual y una virtual que son inseparables y que se presentan contemporáneamente. La imagen percibida nunca está declinada en el presente, ya que se compone por dos imágenes coalescentes que crean una unidad entre la imagen actual y la virtual. Como afirma Engell, la actualización de una implica la virtualización de la precedente.

En este sistema, la actualidad se asegura a través de la continuidad de la imagen, que en su tiempo presente encarna un tiempo presente-cambiante, un gerundio o un tiempo que pasa. Es por esta razón que Engell afirma que la imagen de video es tiempo que se vuelve imagen. La imagen de video representa claramente una imagen que no dura (Sontag, 1973, pp.17-18).

El video, en su sistema de presentación de la realidad, transformando nuestra actividad cognitiva, inició la completa eliminación del presente, de la durée. El intercambio de la duración, del presente, por ese flujo constante en el que lo actual se intercambia por lo virtual determinó la muerte de lo real. La imposibilidad de ser objeto, como en el caso de la imagen de video, determinó la desmaterialización del todo. El continuиm del video se impuso, y, determinando nuestra realidad, disolvió la existencia en intervalos exclusivamente temporales. Y en las sociedades que viven esta nueva cadencia, esta alta velocidad que impacta al presente, el efecto de la realidad se mitiga. En palabras de Baudrillard:

Dans les sociétés trop rapides, comme la nôtre, l'effet de réalité s'estompe : l'accélération fait se bousculer les effets et les causes, la linéarité se perd dans la turbulence, la réa- 
lité, dans sa continuité relative, n'a plus le temps d'avoir lieu. (Baudrillard, 1995, p.72).

En esta nueva cadencia, la imagen se apoderó de nuestra realidad. No una imagen cualquiera. Esta vez, en el contexto tecnológico marcado por la tecnología de video, la imagen no estaba en grado de representar los objetos, ya que era incapaz de contenerlos; por lo tanto, creó una ilusión de los mismos. Sustituyendo la realidad por la virtualidad, la imagen perpetró el delito perfecto.

Durante todas las escenas de Tokyo$G a$ somos testigos de ese delito, que siendo perfecto, no logramos esclarecer, pero sí encontramos sus rastros. Estos últimos se hacen más evidentes después de las primeras escenas de las salas de Pachinko. Por ejemplo, Wenders nos muestra con clara insistencia la marcada e inquietante invasión del espacio por las pantallas televisivas. En un trayecto en taxi, Wenders nos impone un plano de más de dos minutos de la pantalla del televisor instalada en el automóvil. Los planos pierden su delineamiento. Las calles recorridas se funden con las vías hiperrápidas del éter. Es en estas escenas donde se hace clara y casi palpable la sustitución de la realidad por la imagen. Una sustitución que toma forma en las palabras de Wenders. "Perhaps the frantically growing inflation of images has already destroyed too much. Perhaps images at one with the world are already lost forever". Y después de ver en el televisor de un hotel las escenas finales de una película con John Wayne doblado en japonés, Wenders continua:
When John Wayne left, it wasn't the Stars and Stripes that appeared, but rather the red ball of the Japanese flag. And while I was falling asleep, I had the craziest thought: where I am now is the center of the world. Every shitty television set, no matter where, is the center of the world. The center has become a ludicrous idea, and the world as well. An image of the world, a ludicrous idea, the more TV sets there are on the globe. And here I am, in the country that builds them all for the whole world, so that the whole world can watch the American images.

La sustitución de lo real por su simulacro desplazó el punto de vista de del ser humano. Como en el panóptico de Jeremy Bentham, que disloca la relación entre el ver y el ser visto, entre el sujeto y el objeto, la red infinita de imágenes video-electrónicas desplazó al humano. Una red infinita y en continuo devenir, que como un rizoma, transforma radicalmente el espacio. Ahí, en ese rizoma, que ofrece como únicos puntos de contacto, como interfaz, entre lo humano y la realidad, la pantalla de televisión, el sujeto se encuentra como centro momentáneo.

El centro -el humano- encontraría su ser en función del sistema establecido por la red de imágenes electrónicas. Y el ser, como punto de vista sobre la red de imágenes en devenir, se transformaría en una simple parte de ese universo infinito de impulsos eléctricos. De hecho, en ese espacio rizomático, el centro es el punto de vista del sujeto, del humano que mira el entrelazarse de las imágenes video-electrónicas. Wenders resalta el mismo fenómeno. La red de imágenes, en proceso de expansión, empezaba a 
delinear la posibilidad no solo de sustitución de lo real, sino también la posibilidad de finalmente imaginar, aunque en su inmaterialidad, el infinito actual. ${ }^{5}$

Podría parecer una contradicción la precedente afirmación. Si hablamos de infinito actual no podríamos asimilarlo a una entidad inmaterial. Sin embargo, recordemos que uno de los principales fenómenos de la condición postmoderna, así como descrita por Lyotard, es la sustitución de la naturaleza por la información. En palabras de Lyotard, "Lencyclopédie de demain, ce sont les banques de données. Elles excèdent la capacité de chaque utilisateur. Elle sont la «nature » pour l'homme postmoderne." (Lyotard, 1979, pp. 84-85).

La natura para el hombre postmoderno será remplazada por la información. Esta premonición de Lyotard se materializa en cierta forma con las imágenes de Tokyo-Ga, y hoy, en nuestro contexto tecnológico y especialmente después de la creación y popularización del internet, es aún más clara.

Nuestra realidad, nuestra naturaleza, fue traducida y codificada en impulsos eléctricos; estos últimos, con la aparición de la tecnología digital, se convirtieron en bits. Y es por esta razón que hoy, aun teniendo una base recursi- va, estamos en grado de concebir el infinito en nuestra realidad. Podemos percibir el infinito ya que percibimos constantemente una realidad inmaterial que sustituyó al objeto, y es en esa sustitución en la que radica la inmensa y masiva producción de simulacros que hoy pueblan nuestra existencia. Simulacros que componen nuestra realidad e imposibilitan la capacidad de imaginarla, ya que, como afirma Baudrillard, la imagen no puede imaginar lo real, puesto que ella lo es.

Or l'image ne peut plus imaginer le réel, puisqu'elle l'est. Elle ne peut plus le rêver, puisqu'elle en est la réalité virtuelle. C'est comme si les choses avaient avalé leur miroir, et étaient devenues transparentes à elles-mêmes, toutes entières présentes à elles-mêmes, en plein lumière, en temps réel, dans une transcription impitoyable (Baudrillard, 1995, pp.16-17).

La sustitución de lo real es claramente puesta en escena por Wenders en las escenas de la simulación de un juego golf. Practicado por muchos japoneses en su "pura forma", en una práctica de la belleza y la perfección de movimiento, el objetivo real del juego, en estas simulaciones, fue totalmente abandonado. El golf practicado en la Tokio del filme de Wenders se juega en la última

5 A este propósito, recordemos brevemente la distinción entre el infinito actual y el infinito potencial. Ya Aristóteles argumentaba que al hablar de infinito se hacía necesaria la distinción entre el infinito actual y el infinito potencial. El primero, representaba una idea vaga e inaccesible al ser humano. El segundo, el infinito potencial, sería accesible al ser humano a través de su cognición. El infinito potencial es el resultado de una sucesión sin fin, por ejemplo, los números naturales. La sucesión deriva de una operación recursiva que permite un tipo de operación $n+1$. El infinito actual sería entonces inexistente, ya que la percepción humana no estaría en grado de identificar una entidad infinita en magnitud o en su unicidad. En las palabras de Leibniz: Infinitum actu non datur. "Mais on se trompe en voulant s'imaginer un espace absolu qui soit tout infini composé de parties, il n'y a rien de tel (...)" (Leibniz, 1996, p.212). 
planta de un enorme rascacielos, y, en esta simulación, no hay hoyos. Los jugadores golpean en continuación bolas de golf que van a parar contra una red de contención.

El simulacro sustituyó lo real. Y esta sustitución también la presenta Wenders con las escenas del taller donde se confeccionan las réplicas perfectas de los platos desarrollados por la milenaria tradición culinaria japonesa. Una tradición que se extinguía en su réplica de cera, elaborada magistralmente, como testimonia Wenders, en un taller que recuerda un esquema de producción pre-fordista (Alter, 1997, p.143). Esa cocina, definida por Barthes como "enteramente visual" (Barthes, 2002, pp. 367-368), servía de campo para la elaboración de réplicas perfectas: un arte ( $\left.\tau \dot{\varepsilon} \chi_{X} \vee \eta\right)$ que se escapa de la lógica de producción en cadena.

A Wenders le es permitido filmar la casi totalidad del proceso de producción artesanal de estos platos de cera, que, por cierto, en la organización del trabajo que vemos en Tokyo-Ga, la producción inicia con la elaboración de comida real. El único momento que no se le permite filmar a Wenders es la hora de la pausa de los artesanos. En esa hora, de hecho, ellos consumían alimentos, que según Wenders: "All the employees sat amidst their wax creations and ate the food they had brought, which looked exactly like the imitations all around them. You could almost imagine one of them biting into a wax roll by mistake”. A este propósito, Alter afirma lo siguiente:

Thus the only live moment of restorationthat is, biological incorporation-eludes the eye of the camera. In a sense, of course, this manufacturing of seductive, deceptive, simulacrum dishes is not dissimilar from filmmaking. The creation of fake food starts with real food that is fixed with artful means, just as real life is artfully fixed on celluloid when it becomes cinematic images. It is as if the materialist-modernist slogan man ist, was man ißt (one is what one eats) has become a postmodernbut still materialist- man ist, was man siehst (one is what one sees) (Alter, 1997, p.143).

Las escenas del taller donde se realizan las réplicas de cera nos muestran el pasaje de un mundo tangible a uno virtual, que sin embargo sigue siendo material. Desde nuestro presente, marcado por la tecnología digital, podemos ver en esas escenas que se perpetraba el crimen. Pocos años después entraríamos a un contexto digital que ejercería su gran poder de desmaterialización de lo real: como afirma Baudrillard, la imagen no puede imaginar lo real, puesto que ella lo es. Y es en ese sentido que podríamos interpretar las palabras de Wener Herzog pronunciadas durante su corta aparición en Tokyo-Ga.

En la cúspide de la Tokyo Tower, que ofrece una espléndida vista panorámica sobre la ciudad, Herzog afirma que no quedan imágenes, que ya han desaparecido. Encontrarlas requiere una misión arqueológica y buscarlas implica un riesgo. El crimen se perpetraba. Lo real desaparecía e imposibilitaba la realización de la imagen puesto que todo era ya una imagen, y, sobre todo, el conjunto empezaba a ser un bit. 
Herzog evoca de nuevo la figura del arqueólogo (Man muss also wie ein Archäologe mit dem Spaten graben) para poder encontrar algo (irgendetwas finden kann), para procurar una imagen que signifique algo para nuestra civilización, que signifique algo para nuestro ser (Wir brauchen ganz unbedingt Bilder, die mit unserem Zivilisationsstand und mit unserem Inneren, allertieften, übereinstimmen).

\section{Conclusiones}

Desde el inicio de Tokyo-Ga, Wenders se propone como un arqueólogo que va en búsqueda de esas imágenes, de imágenes transparentes, como las llama Herzog. Wenders, a través de la obra de $\mathrm{Ozu}$, se dedica a buscar imágenes reales o vestigios de una humanidad que, reconociéndose como sujeto, establecía una relación con el objeto, con lo real. Tal y como señala Alter, en Tokyo-Ga Wenders nos muestra la imposibilidad de tener una visión, o un significado ajeno a la mediación tecnológica:

As recorded by Wenders camera, the most significant sequences seem at first glance to involve an overall loss of essence, a loss of something like the possibility of an unmediated vision or meaning. They show a world dominated by mass-media images, artificial signs of an alienated hypereality (Alter, 1997, p.142).

Wenders, en su investigación arqueológica, nos muestra que la sustitución de lo real fue perfecta. No hay trazos de ello. En Tokyo-Ga vemos algunos rastros del pasado: hoy hecho imagen. Vemos cómo nuestras tecnologías, por decirlo à la Baudrillard, no son otra cosa que un instrumento de un mundo que creemos controlar y que por el contrario es ese mundo que se impone gracias a los dispositivos y aparatos (Baudrillard, 1995, p.106).

En Tokyo-Ga no queda más que la sensación de vacío. El mismo vacío creado por la amnesia en las salas de Pachinko. Un vacío generado por la imposibilidad de percibir las relaciones entre objetos y sujetos, debido a que el objeto se perdió en su simulacro y el sujeto se enajenó de la realidad. Tokyo-Ga nos presenta la incapacidad de encontrar no solo el significado, sino la imagen, el objeto (Flusser, 1996, p.21). Se podría afirmar que la posibilidad de un infinito actual es la fuente del vacío, ya que la hiperconexión, la hiperrealidad es la ausencia del espacio, entendido como serie de relaciones. Si bien el Analysis Situs y la topología nos habían ayudado a comprender el espacio no como un 'contenedor' de objetos, sino como una serie de relaciones entre objetos y sujetos (Foucault, 1984, p.47), con Tokyo-Ga podemos darnos cuenta que la hiperconectividad terminó por sustituir el espacio, absorbiendo al sujeto y haciéndolo parte conectora del propio dispositivo.

Afirmábamos, a través de las reflexiones de Nora Alter, que Wenders en Tokyo-Ga nos había mostrado la pérdida del sentido a causa de la imposibilidad de la existencia de un evento que no fuera mediado. Afirmábamos que Wenders nos mostraba un mundo dominado por las imágenes producidas por los medios de comunicación de masas. Ese era el cuerpo del delito. Lo real, que nunca 
pudimos encontrar en el filme, pero que su desaparición probaba el crimen. Sin embargo, mientras Wenders buscaba lo real, guiándose con las pruebas de su existencia a través de la obra de Ozu, se perpetraba otro crimen: el medio empezaba a desaparecer.

En las imágenes de Tokyo-Ga vemos cómo se orquestaba la muerte del medio. De hecho, en Tokyo-Ga vemos que la red de imágenes video-electrónicas empezaba a generar la necesidad de invadir el espacio con medios. Como afirmábamos, el sujeto mismo se empezaba a convertir en un medio, y con la desaparición del espacio se sentenció la desaparición del medio (Eugeni, 2015). En las palabras de Antonio Caronia, el cuerpo se convirtió interfaz (Caronia, 2008, pp.105-109), y esto sentenció la inutilidad del medio, sentenció su desaparición: el crimen perfecto.

\section{Referencias Bibliográficas}

Anderson J. L., y Richie D. (1960). The Japanese Film: Art and Industry. New York: Grove Press.

Alter, N. (1997). Documentary as Simulacrum: Tokyo-Ga. En R. F. Cook y G. Gemüden (Eds.), The Cinema of Wim Wenders: Image, Narrative, and the Postmodern Condition (pp. 136162). Detroit: Wayne State University Press.

Bachelard, G. (1931). L'Intuition de l'instant. Paris: Stock.

Barthes, R. (2002). L'empire des signes. En Oeuvres complètes, tomo III, libres, textes, entretiens 1968-1971. Lonrai: Seuil.

Baudrillard, J. (1995). Le crime parfait. Paris: Éditions Galilée.

Bazin, A. (2008). Que'est-ce que le cinéma? Paris: Éditions du Cerf.

Bordwell, D. (1988). Ozu and the Poetics of Cinema. Princeton: Princeton University Press.

Caronia, A. (2008). Il cyborg. Saggio sull'uomo digitale. Milano: Shake Edizioni.

Deleuze, G. (1966). Le bergsonisme. Paris: Puf.

Deleuze, G. (1968). Différence et répétition. Paris: Puf.

Dorfles, G. (2008). Horror pleni. La (in)civiltà del rumore. Roma: Castelvecchi.

Engell, L. (1999). Fernsehen mit Gilles Deleuze. En O. Fahle y L. Engell (Eds.), Der Film bei Deleuze / Le cinéma selon Deleuze (pp. 468-481). Weimar: Verlag der Bauhaus-Universität/ Presses de la Sorbone Nouvelle.

Eugeni, R. (2015). La condizione postmediale. Milano: La scuola.

Flusser, V. (1996), Ins universum der Technischen Bilder. Göttingen: European Photography.

Foucault, M. (1984). Des espaces autres. Architecture, Mouvement, Continuité (n. 5 -octobre 1984), pp. 46-49.

Halbwachs, M. (1997). La mémoire collective. Paris: Éditions Albin Michel.

Herrigel, E. (1999). Zen in the Art of Archery. New York: Vintage Books.

Hume, D. (2000). A Treatise of Human Nature. Oxford: Oxford University Press.

Lefebvre, M. (1999). On memory and Imagination in the Cinema. New Literary History Cultural Inquiries (Vol. 30, N. 2) pp. 479-498. The John Hopkins University Press. 
Leibniz, G. W. (1996) $)^{(1765)}$. Nouveaux essais sur l'entendement humain / Neue Abhandlungen über den menschlichen Verstand. En G. W. Leibniz, Philosophische Schriften Band 3.1 y 3.2. W. von Engelhardt y H. H. Holz. (Eds.), Frankfurt am Main: Suhrkamp.

Liverani, M. (2009). Antico Oriente. Storia, società, economia. Roma-Bari: Laterza.

Lyotard J. F. (1979). La condition postmoderne. Paris: Minuit.

McLuhan M. (1994). Understanding Media: The Extensions of Man. Cambridge Massachusetts: MIT.

Monico F. y De Kerckhove, D. (2016). Cyber-sorveglianza, guerra e religione. Il mondo a una dimensione. Azimuth. Philosophical Coordinates in Modern and Contemporary Age, (IV n. 7).

Ozu, Y. (1970). Ozu on Ozu: The Talkies. Cinema (6. No. 1).

Richie, D. (1959). The Late Films of Yasujiro Ozu. Film Quarterly (13.1 - Fall 1959).

Richie, D. (1962). Japanese Movies. Tokio: Japan Travel Bureau.

Sontag, S. (1973). On Photography. New York: Picador.

Spielmann Y. (2005). Video. Das reflexive Medium. Frankfurt am Main: Suhrkamp.

Sugimoto, Y. (2010). An Introduction to Japan Society. Cambridge: Cambridge University Press.

Suzuki, D. T. (1964). An introduction to Zen Buddhism. New York: Grove.

Thrift, N. (2007). Non-Representational Theory. London: Routledge.

Tomasi, D. (1996). Ozu Yasujiro, viaggio a tokio. Torino: Lindau. 